\title{
Article \\ Post-Contrast Acute Kidney Injury in Patients with Various Stages of Chronic Kidney Disease-Is Fear Justified?
}

\author{
Inga Chomicka, Marlena Kwiatkowska, Alicja Lesniak and Jolanta Malyszko * $\mathbb{D}$ \\ Department of Nephrology, Dialysis and Internal Medicine, Medical University of Warsaw, Banacha 1A, \\ 02-097 Warsaw, Poland; inga.chomicka@wum.edu.pl (I.C.); mkwiatkowska1@wum.edu.pl (M.K.); \\ alicja.lesniak@uckwum.pl (A.L.) \\ * Correspondence: jolmal@poczta.onet.pl
}

Citation: Chomicka, I.;

Kwiatkowska, M.; Lesniak, A.; Malyszko, J. Post-Contrast Acute Kidney Injury in Patients with Various Stages of Chronic Kidney Disease-Is Fear Justified? Toxins 2021, 13, 395. https://doi.org/ $10.3390 /$ toxins 13060395

Received: 1 May 2021

Accepted: 27 May 2021

Published: 1 June 2021

Publisher's Note: MDPI stays neutral with regard to jurisdictional claims in published maps and institutional affiliations.

Copyright: (C) 2021 by the authors. Licensee MDPI, Basel, Switzerland. This article is an open access article distributed under the terms and conditions of the Creative Commons Attribution (CC BY) license (https:/ / creativecommons.org/licenses/by/ $4.0 /)$.

\begin{abstract}
Post-contrast acute kidney injury (PC-AKI) is one of the side effects of iodinated contrast media, including those used in computed tomography. Its incidence seems exaggerated, and thus we decided to try estimate that number and investigate its significance in our clinical practice. We analyzed all computed tomographies performed in our clinic in 2019, including data about the patient and the procedure. In each case, we recorded the parameters of kidney function (serum creatinine concentration and eGFR) in four time intervals: before the test, immediately after the test, 14-28 days after the test, and over 28 days after the test. Patients who did not have a follow-up after computed tomography were excluded. After reviewing 706 CT scans performed in 2019, we included 284 patients undergoing contrast-enhanced CT and 67 non-enhanced CT in the final analysis. On this basis, we created two comparable groups in terms of age, gender, the severity of chronic kidney disease, and the number of comorbidities. We found that AKI was more common in the non-enhanced CT population ( $25.4 \%$ vs. $17.9 \%$ ). In terms of our experience, it seems that PC-AKI is not a great risk for patients, even those with chronic kidney disease. Consequently, the fear of using contrast agents is not justified.
\end{abstract}

Keywords: acute kidney injury; iodinated contrast media; computed tomography; post-contrast acute kidney injury

Key Contribution: The aim of our study was to determine the prevalence of post-contrast acute kidney injury after contrast-enhanced computed tomography in patients at various stages of chronic kidney disease. This result was compared with the incidence of acute kidney injury after computed tomography without contrast enhancement.

\section{Introduction}

Intravenous iodine contrast agents have been used in medicine for over one hundred years, since 1923 when Osborne and colleagues from the Mayo Clinic performed urography [1]. The first reports of post-contrast acute kidney injury (PC-AKI) appeared in 1945, when Bartel and associates described anuria after pyelography [2]. Then, an avalanche of research began to identify risk factors, possible prophylactic measures, long-term effects of post-contrast acute kidney injury, and also attempts to reduce nephrotoxicity of iodinated contrast agents. It would seem that during these almost one hundred years it should have been possible to establish the principles of safe use of iodinated contrast media. The truth is that PC-AKI still remains a controversy that requires more research.

According to the latest ESUR Contrast Medium Safety Committee guidelines, postcontrast acute kidney injury is defined as an increase in serum creatinine concentration $\geq 0.3 \mathrm{mg} / \mathrm{dL}$ or $\geq 1.5-1.9$ times the baseline value (AKI definition according to KDIGO) within $48-72 \mathrm{~h}$ after contrast medium administration. It is also worth noting that the guidelines distinguish the contrast-induced acute kidney injury (CI-AKI), which is similarly defined as PC-AKI, but diagnosis requires the exclusion of all possible causes of renal 
failure $[3,4]$. However, it seems that using this diagnosis in clinical practice carries a risk of bias, as we cannot absolutely exclude the influence of all potential nephrotoxic agents. It is also a major difficulty in determining the actual risk of kidney damage and the frequency of PC-AKI.

In the first publications about PC-AKI, it was estimated that it occurs in up to 55\% of people with reduced glomerular filtration. At that time, it was also claimed that the administration of iodinated contrast agents was the most common cause of AKI among hospitalized patients [5]. For this reason, very careful and strict qualification of patients for procedures requiring the administration of iodinated contrast media was performed, even for contrast-enhanced computed tomography. For example, a few years ago, the condition for the examination, even in patients with normal kidney function, was to withdraw metformin earlier, but now we know that it does not increase the risk of PC-AKI in this group and can be safely used [6,7]. It seems that these restrictions mostly affect patients with chronic kidney disease, which is an evident risk factor for the development of PC-AKI. There are no data on the number of cases in this group of patients where contrast-enhanced computed tomography was denied and diagnosis was delayed-we can only guess. A few years ago, a survey was conducted in which radiologists were asked about their clinical practice. According to that survey, up to $36 \%$ of radiologists declared that they do not perform contrast-enhanced CT in patients with multiple myeloma. Moreover, approximately $11 \%$ of the respondents answered that they did not perform contrast-enhanced CT in patients after kidney transplantation [8].

Currently, there are reports of a lower incidence of PC-AKI than before [5,9]. However, the unequivocal statement about the overestimation of the prevalence of PC-AKI requires confirmation in further studies. This gives hope for change in the current procedure and more liberal approach to qualification for contrast-enhanced tomography, faster diagnostics, and implementation of treatment. For this purpose, we first decided to estimate the incidence of AKI after computed tomography with iodine contrast in a small group of patients hospitalized in our department, as described in an earlier publication. We obtained interesting results that encouraged us to continue working in a larger group of patients [10].

\section{Results}

In 2019, a total of 706 computed tomographies were conducted at our Nephrology, Dialysis, and Internal Medicine Department. Of these, 128 examinations were performed on dialysis patients, including 92 contrast-enhanced CT and 36 non-enhanced CT. The above cases were not included in the further analysis, as assumed. After excluding examinations without subsequent control of renal parameters, we included 284 contrast-enhanced CT and 67 non-enhanced CT in the final analysis. At this stage, we can conclude that our department performed significantly more contrast-enhanced CT. It seemed that this was not characteristic of only 2019, but a similar disproportion was also present in previous years. However, we are not able to quote specific numbers as this was not the subject of our study.

By analyzing the characteristics of the ordered computed tomography, we can conclude that in the case of contrast-enhanced $\mathrm{CT}$, we performed urgent and routine examinations with similar frequency (143 vs. 141). However, non-enhanced CT was more often performed urgently than planned (43 vs. 24). (Figure 1) Efforts were made to maintain euvolemia and preserved diuresis before and after the examination in each patient undergoing contrast-enhanced CT. Taking into account the state of hydration and the patient's burden, in some cases oral or intravenous hydration was used. In addition, potentially nephrotoxic drugs were discontinued $24 \mathrm{~h}$ prior to CT. In individual cases, acetylcysteine was also used. We also considered how many examinations were performed according to one protocol (i.e., only abdomen or chest or head etc.), two (i.e., abdomen + chest or chest + head or abdomen + head, etc.) or more. In the case of contrast-enhanced CT, 179 tests (63\%) were based on one protocol, 86 tests $(30.3 \%)$ on two, and 19 tests $(6.7 \%)$ on more. Correspondingly, in CT without contrast enhancement, 58 tests $(86.6 \%)$ were performed with one protocol, 7 tests 
$(10.4 \%)$ with two, and 2 tests (3\%) with more protocols. In our center, three types of iodine contrast agents were used: iomeprol, iopromide, and iodixanol. Two of them, iomeprol and iopromide, are low-osmolarity contrast agents, while iodixanol is the only iso-osmolar agent. After the analysis of the performed CT, we were able to safely assert that LOCM (low-osmolal contrast medium) was strongly preferred in our hospital-iomeprol was used in 149 examinations, and iopromide in 102 examinations. IOCM (iso-osmolal contrast medium) was only used in isolated cases - only seven iodixanol-enhanced examinations were performed in 2019. The average doses of iodine contrast agent were $76.99 \mathrm{~mL}$ for iomeprol, 78.43 for iopromide, and $88.57 \mathrm{~mL}$ for iodixanol.
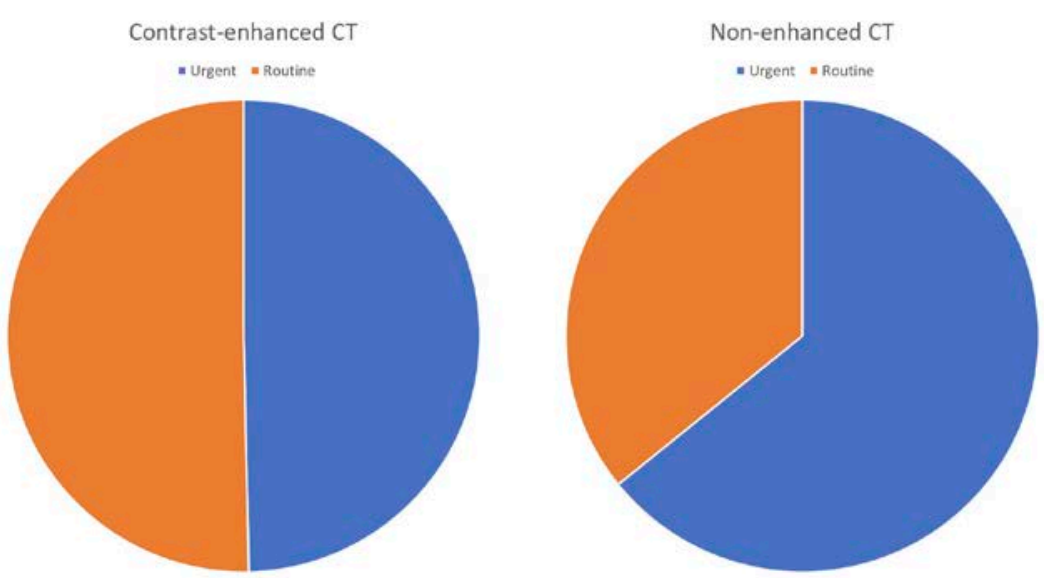

Figure 1. The figure shows the quantitative share of computed tomographies performed urgently (blue) and scheduled (orange). The graph on the right represents tomography performed with contrast enhancement (52.5\% urgent), the one on the left without enhancement (35.8\% urgent).

Moving on to the main assumption of our study, we looked at serum creatinine and eGFR in all patients who underwent computed tomography. We tracked the parameters of kidney function in all these patients at four time points: before computed tomography, 1-7 days after CT (mainly 1-2 days), 14-28 days after CT, and more than 28 days after the study. The mean serum creatinine level and eGFR were calculated for each time interval, as shown in the attached table (Table 1). We found 44 cases of AKI in patients undergoing contrast-enhanced CT, i.e., PC-AKI, representing $15.5 \%$ of all patients undergoing this type of CT. Similarly, in the case of non-contrast tomography, we found 17 cases of AKI, which is as much as $23.9 \%$. The analysis of renal parameters among patients with AKI was performed analogous to the analysis in the entire study population. In this case, mean values of serum creatinine and eGFR were also calculated the four time points mentioned above (Table 2). Both patient populations were of similar age-the mean age of patients after CT with contrast was 65.1, and for patients after CT without contrast, 71. The gender distribution was also relatively similar in both groups. Among patients undergoing contrast-enhanced CT, there were 135 women $(47.5 \%)$ and 149 men (52.5\%), while non-enhanced CT was performed on 35 women $(52.2 \%)$ and 32 men (47.8\%). We also analyzed the presence of comorbidities among patients, which in our opinion could have influenced the development of AKI, including PC-AKI. The table shows their incidence in both populations (Table 3).

We realize that despite the above-mentioned similarities, due to the disproportion in numbers, we cannot draw a firm conclusion about the higher incidence of AKI after non-enhanced CT. Due to this fact, we tried to choose patients of similar sex, age, and number of comorbidities in both groups (contrast-enhanced CT and non-enhanced CT). On this basis, two groups with similar characteristics were created, representing different stages of CKD defined according to KDIGO [11] (Figure 2). The incidence of AKI after CT was reanalyzed, resulting in 12 cases of AKI after contrast-enhanced CT (which is $17.9 \%$ ) and 17 cases of AKI after non-enhanced CT (which is 25.4\%) (Figure 3). This is quite 
surprising as it suggests that contrast administration and its effect on the kidneys does not significantly increase the incidence of AKI in hospitalized patients. We analyzed the indications for CT in both study groups, mostly finding life indications, which confirms our assumption that patients were referred for examination on the basis of indications and not on parameters of kidney function (Tables 4 and 5).

Table 1. Serum creatinine and eGFR in patients undergoing computed tomography with and without contrast.

\begin{tabular}{|c|c|c|c|c|}
\hline & Before CT & 1-7 Days after & 14-28 Days after & $>28$ Days after \\
\hline $\begin{array}{c}\text { CT without contrast creatinine, } \\
\mathrm{mg} / \mathrm{dL}\end{array}$ & $1.16(1.06 ; 10.61)$ & $1.54(1.12 ; 7.18) * \# \#$ & $1.44(0.49 ; 12.98)$ *\#\# & $1.04(0.21 ; 7.81)$ \\
\hline $\begin{array}{c}\text { CT without contrast eGFR, } \\
\mathrm{mL} / \mathrm{min} / 1.73 \mathrm{~m}^{2}\end{array}$ & $50(5 ; 120) \#$ & $39(7 ; 120) \# \#$ & 45(4; 102) \#\# & $72(7 ; 120)$ \\
\hline $\begin{array}{c}\text { CT with contrast creatinine, } \\
\mathrm{mg} / \mathrm{dL}\end{array}$ & $0.99(0.48 ; 8.73)$ & $1.06(0.33 ; 8.07)$ & $0.96(0.36 ; 7.85)$ & $1.00(0.49 ; 5.84)$ \\
\hline $\begin{array}{c}\text { CT with contrast eGFR, } \\
\mathrm{mL} / \mathrm{min} / 1.73 \mathrm{~m}^{2}\end{array}$ & $68(7 ; 120)$ & $66(7 ; 120)$ & $74(7 ; 120)$ & $70(8 ; 120)$ \\
\hline
\end{tabular}

Data given are medians and minimum-maximum; ${ }^{*} p<0.05,{ }^{* *} p<0.01$ vs. baseline values before CT; \# $p<0.05$, \#\# $p<0.01 \mathrm{CT}$ with vs. without contrast.

Table 2. Serum creatinine and eGFR in patients with AKI undergoing computed tomography with and without contrast.

\begin{tabular}{|c|c|c|c|c|}
\hline & Before CT & 1-7 Days after & 14-28 Days after & $>28$ Days after \\
\hline $\begin{array}{l}\text { CT without contrast creatinine, } \\
\mathrm{mg} / \mathrm{dL}\end{array}$ & $1.22(0.74 ; 10.61)$ & $1.73(0.70 ; 6.77)^{* *}$ & $1.75(1.00 ; 9.20) * *$ & $1.71(0.93 ; 7.81)$ * \\
\hline $\begin{array}{c}\text { CT without contrast eGFR, } \\
\mathrm{mL} / \mathrm{min} / 1.73 \mathrm{~m}^{2}\end{array}$ & $46(9 ; 120)$ & $31(7 ; 86)^{* *}$ & $34(4 ; 69)^{* *}$ & $31(7 ; 116) *$ \\
\hline $\begin{array}{c}\text { CT with contrast creatinine, } \\
\mathrm{mg} / \mathrm{dL}\end{array}$ & $1.29(0.67 ; 6.17)$ & $1.46(0.67 ; 6.53) * \#$ & $1.56(0.64 ; 4.03) * * \#$ & $1.77(0.64 ; 4.74)$ * \\
\hline $\begin{array}{c}\text { CT with contrast eGFR, } \\
\mathrm{mL} / \mathrm{min} / 1.73 \mathrm{~m}^{2}\end{array}$ & $53(8 ; 20) \#$ & $37(7 ; 91) * \#$ & $40(7 ; 87) \#$ & $34(8 ; 116)$ \\
\hline
\end{tabular}

Data given are medians and minimum-maximum; ${ }^{*} p<0.05,{ }^{* *} p<0.01$ vs. baseline values before CT; $\# p<0.05$ CT with vs. without contrast.

Table 3. Comorbidities—number and percentage share (in parentheses).

\begin{tabular}{ccc}
\hline Comorbid Disease & $\begin{array}{c}\text { Participation in the } \\
\text { Population Subjected to } \\
\text { Contrast-Enhanced CT }\end{array}$ & $\begin{array}{c}\text { Participation in the } \\
\text { Population Subjected to } \\
\text { Non-Enhanced CT }\end{array}$ \\
\hline Cancer & $72(25.4 \%)$ & $10(14.9 \%)$ \\
Hypertension & $181(63.7 \%)$ & $50(74.6 \%)$ \\
Diabetes mellitus & $77(27.1 \%)$ & $12(17.9 \%)$ \\
COPD 1 /asthma & $39(13.7 \%)$ & $11(16.4 \%)$ \\
Chronic heart failure & $67(23.6 \%)$ & $24(35.8 \%)$ \\
Coronary heart disease & $58(20.4 \%)$ & $13(19.4 \%)$ \\
Cirrhosis & $18(6.3 \%)$ & $3(4.5 \%)$ \\
Thyroid disease & $6(2.1 \%)$ & $1(1.5 \%)$ \\
Sepsis/severe infection & $74(26 \%)$ & $29(43.3 \%)$ \\
Anemia & $169(59.5 \%)$ & $47(70.1 \%)$ \\
Pulmonary embolism & $21(7.4 \%)$ & $3(4.5 \%)$ \\
\hline
\end{tabular}

${ }^{1}$ COPD—chronic obstructive pulmonary disease.

Table 4. Indications for contrast-enhanced CT in the studied group of patients.

\begin{tabular}{cc}
\hline Indication & Number of Patients $(\boldsymbol{n}=\mathbf{2 8 5})$ \\
\hline Pulmonary embolism & 21 \\
Abscess & 7 \\
Neoplastic disease (diagnosis or stage assessment) & 29 \\
Vascular complications & 3 \\
Other & 7 \\
\hline
\end{tabular}




\section{Stages of CKD in the study population (percentage and attendance) \\ Without contrast $\mathbf{w i t h}$ contrast}

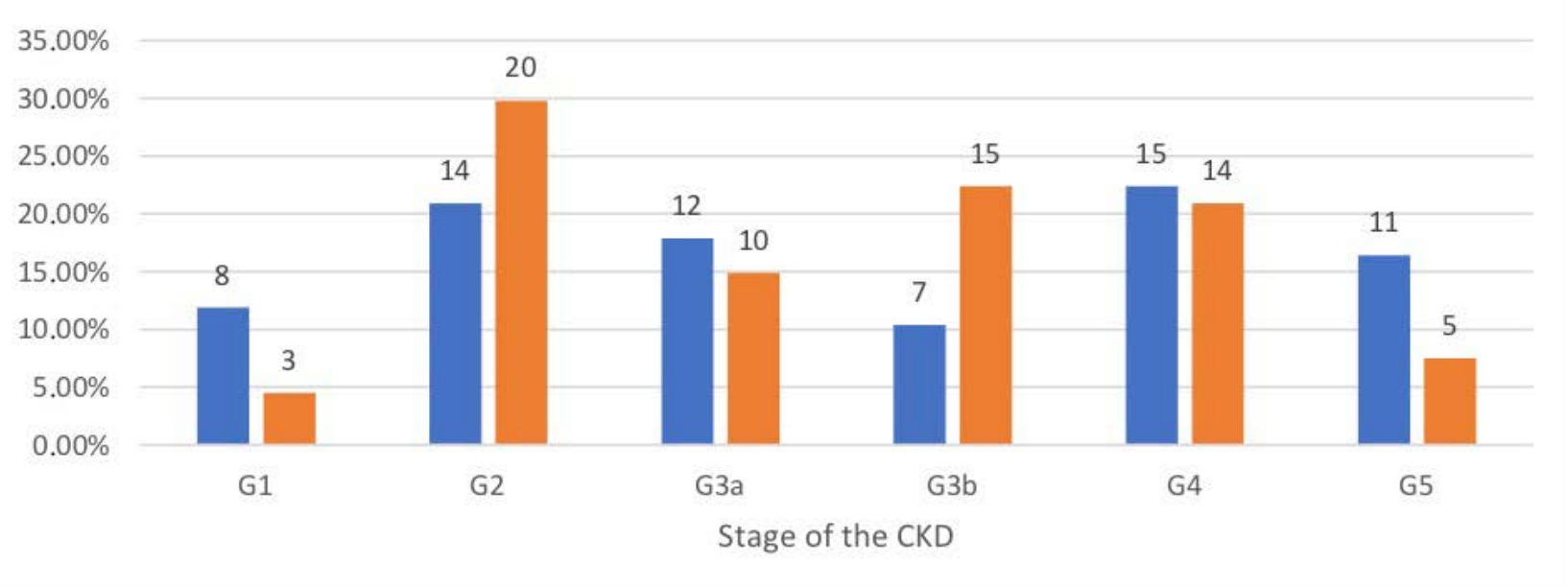

Figure 2. The figure shows the participation of chronic kidney disease stages in both study groups.

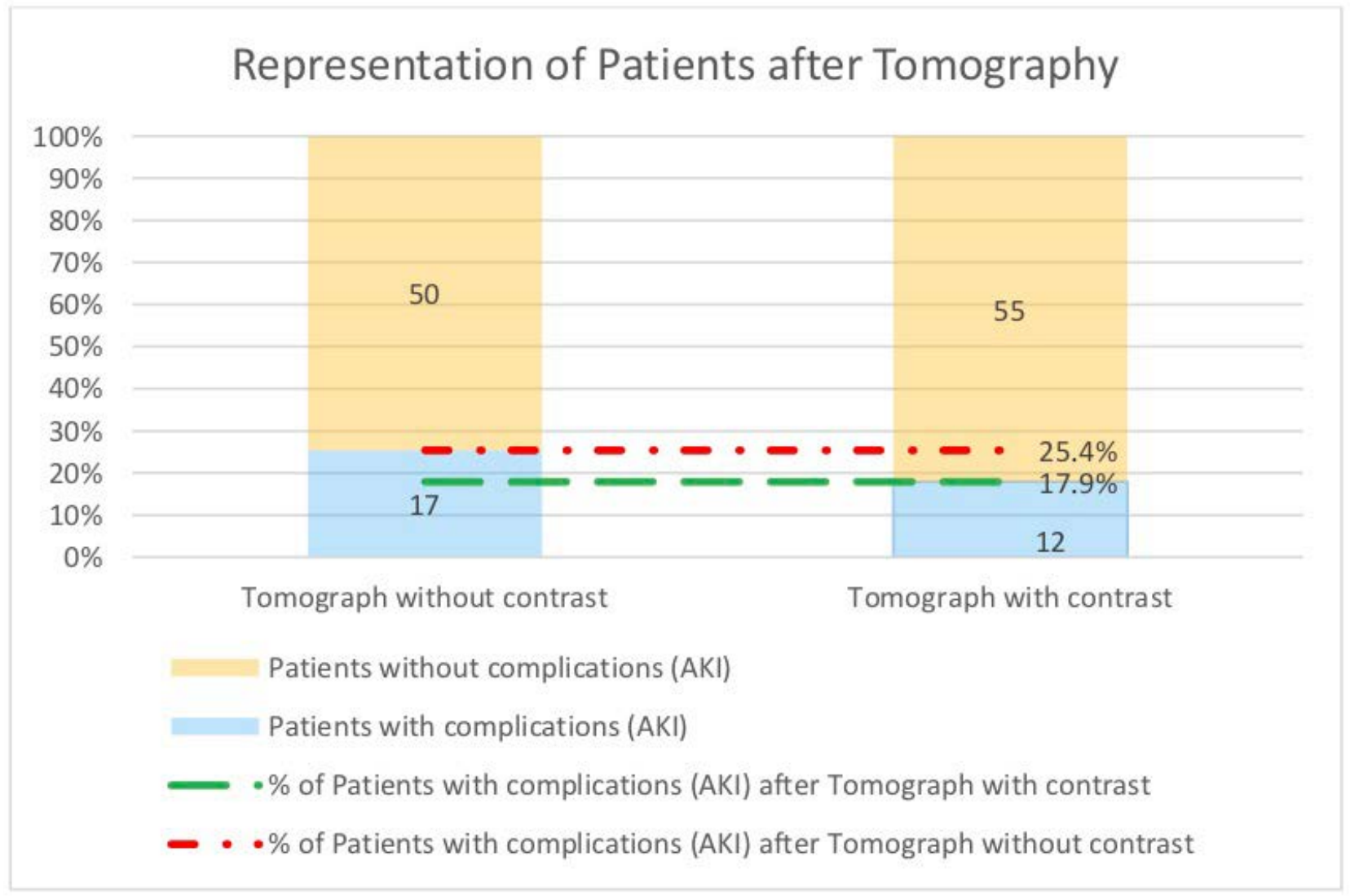

Figure 3. Incidence of acute kidney injury after non-enhanced and contrast-enhanced CT. The figure shows the percentage of the population diagnosed with AKI after the examination. 
Table 5. Indications for non-enhanced CT in the studied group of patients.

\begin{tabular}{cc}
\hline Indication & Number of Patients $(\boldsymbol{n}=\mathbf{6 7})$ \\
\hline Vasculitis & 6 \\
Fracture/bone metastases & 13 \\
Stroke/intracranial bleeding & 14 \\
Sinusitis & 6 \\
Pneumonia/pulmonary fibrosis & 16 \\
Other & 12 \\
\hline
\end{tabular}

Regardless of whether or not iodine-based contrast agents were administered, we can clearly state that greater risk of AKI occurs after performing emergency tomography. Among the CT with administration of iodinated contrast media, there were 10 cases of AKI out of 37 emergency examinations (estimated risk of AKI 27\%) and 2 cases of AKI out of 30 routine examinations (estimated risk of AKI 6.7\%). A similar situation occurred in the case of emergency non-enhanced CT, where 12 cases of AKI were registered out of 43 tests performed (estimated risk of AKI 27.9\%). Noteworthy is the number of AKI cases after routine CT without contrast administration-as many as 5 cases of AKI were registered out of 24 examinations (estimated risk of AKI 20.8\%) (Table 6). The type of contrast used probably did not influence the development of AKI. In the contrast-enhanced CT that were included in the final analysis, two types of iodinated contrast media were used: iopromide and iomeprol. AKI was found in approximately $19.2 \%$ of the CT with administration of iopromide and $18.2 \%$ with administration of iomeprol.

Table 6. The occurrence of AKI depending on the mode of CT.

\begin{tabular}{cccc}
\hline Type of Examination & Urgent & Routine \\
\hline \multirow{3}{*}{ Contrast-enhanced CT } & Number of AKI cases & 10 & 2 \\
& Total number of CT & 37 & 30 \\
& AKI frequency & $27 \%$ & $6.7 \%$ \\
\hline \multirow{3}{*}{ Non-enhanced CT } & Number of AKI cases & 12 & 5 \\
& Total number of CT & 43 & 24 \\
& AKI frequency & $27.9 \%$ & $20.8 \%$ \\
\hline
\end{tabular}

Additionally, we assessed patients in both study groups who developed acute kidney injury in both study groups (contrast-enhanced CT and non-enhanced CT), in terms of age, number of comorbidities, and the stage of chronic kidney disease. Thus, we can conclude that one of the factors increasing the risk of AKI after CT is advanced age (above the age of 70 , according to our study). In addition, it seems that the number of comorbidities did not increase that risk. On average, in the group of patients undergoing non-enhanced CT, we found four comorbidities, and in the group of patients undergoing contrast-enhanced CT, we found 3.9. For both groups that developed AKI, the mean number of comorbidities was 4.4 , regardless of contrast was administration. After analyzing the number of AKI episodes in specific stages of chronic kidney disease (CKD), we found no obvious relationship between the two. An interesting finding is the fact that $58.3 \%$ of people with AKI after contrast-enhanced CT had advanced CKD before the procedure (i.e., G3b, G4, and G5 stages). On the other hand, in patients undergoing non-contrast CT, the percentage of cases with advanced CKD that developed AKI was $47.1 \%$. This was not a large difference, and thus in order to unambiguously associate the higher incidence of AKI in advanced CKD after contrast administration, we argue that the study group should be larger (Figure 4). The group in the G3b stage seemed to be most interesting because only in this group did we find more frequent AKI cases after contrast-enhanced CT. However, justifying this thesis would require research on a larger population. 


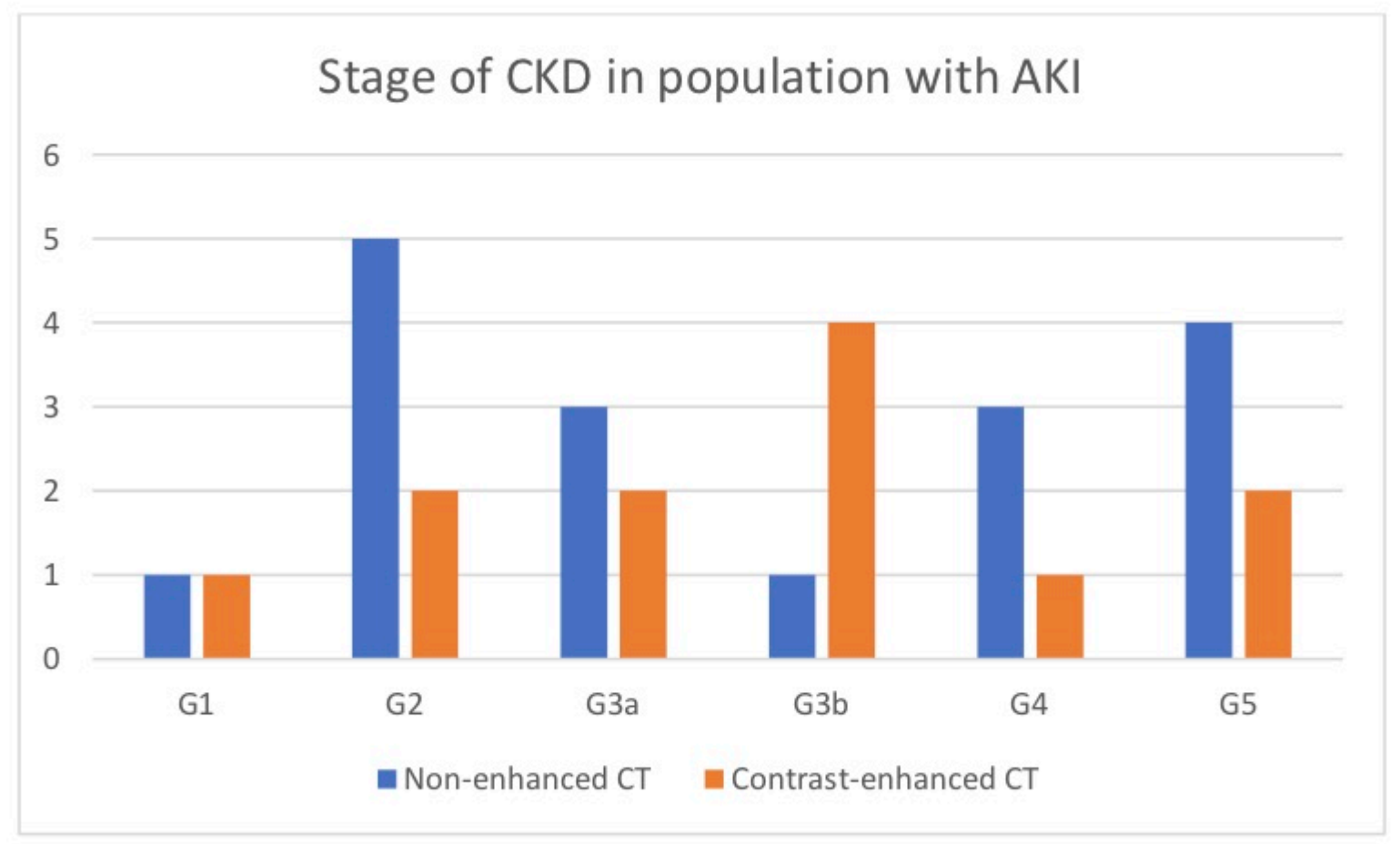

Figure 4. Number of patients at particular stages of chronic kidney disease who were diagnosed with AKI after computed tomography (including whether iodinated contrast media was administered).

\section{Discussion}

In our study, we assessed patients in both study groups who developed acute kidney injury in both study groups (contrast-enhanced CT and non-enhanced CT), in terms of age, number of comorbidities, and the stage of CKD per KDIGO definition [11]. Thus, we can conclude that one of the factors increasing the risk of AKI after CT is advanced age (above the age of 70, according to our study). In addition, it seems that the number of comorbidities did not increase that risk. On average, in the group of patients undergoing non-enhanced $\mathrm{CT}$, we found four comorbidities, and in the group of patients undergoing contrast-enhanced CT, we found 3.9. For both groups that developed AKI, the mean number of comorbidities was 4.4, regardless of contrast, was administration. After analyzing the number of AKI episodes in specific stages of CKD, we found no obvious relationship between the two. An interesting finding is the fact that $58.3 \%$ of people with AKI after contrast-enhanced CT had advanced CKD before the procedure (i.e., G3b, G4, and G5 stages). On the other hand, in patients undergoing non-contrast $\mathrm{CT}$, the percentage of cases with advanced CKD that developed AKI was $47.1 \%$. This was not a big difference, and thus to unambiguously associate the higher incidence of AKI in advanced CKD after contrast administration, we argue that the study group should be larger (Figure 4). The group in the G3b stage seemed to be most interesting because we found more frequent AKI cases after contrast-enhanced CT only in this group. However, justifying this thesis would require research on a larger population.

In addition, we would like to stress that the rise in serum creatinine seen at more than 28 days in the contrast group could not be attributed to the contrast administration. Data were collected form the medical charts from the hospital or outpatient charts (another hospitalization, infection, dehydration, worsening of heart failure, acute coronary syndrome, etc.). Therefore, they were not relevant to the CI-AKI.

Our study indirectly demonstrated that the problem of PC-AKI after computed tomography seems to be exaggerated. This finding is also supported by two large meta-analyses, where a total of 19,000 patients were examined, and the incidence of PC-AKI was estimated to be 5.0-6.4\%, which is significantly lower than previously thought $[12,13]$. In these two papers, first of all, serum creatinine was measured in the vast majority after 
2-3 days [12-14], while we did measure creatinine immediately after the CT, i.e., within 1-2 days, and thus several cases could have been missed in the studies included in the meta-analysis [12]. In addition, some of the studies were small, with 19 or 20 patients. In the largest study included in the meta-analysis on 11,516 patients with serum creatinine assessed after 7 days, CI-AKI incidence was $11.7 \%$ [13]. In the recent KOMPAS trial assessing the renal safety of omitting prophylactic prehydration prior to iodine-based contrast media administration in patients with stage 3 CKD, PC-AKI occurred in 11 patients $(2.1 \%)$, including 7 of $262(2.7 \%)$ in the no prehydration group and 4 of $261(1.5 \%)$ in the prehydration group [15]. They evaluated serum creatinine after 2 to 5 days after contrast administration, and therefore their incidence of PC-AKI was relatively low as they may have missed several cases [15]. In our study, we assessed the incidence of acute kidney injury in relation to contrast administration. In the NICIR study, PC-AKI rate was $4.4 \%$ (95\% CI: $1.4-9.9 \%)$ in the oral hydration arm and 5.3\% (95\%CI: $2.0-11.1 \%)$ in the i.v. hydration arm [16]. They also assessed serum creatinine within $48-72 \mathrm{~h}$ after the procedure. In the study by Chaudhury et al. [17] from the Cleveland Clinic CKD registry, the incidence of AKI was $27 \%$ in the coronary angiography group, $24 \%$ in CT with contrast, and $24 \%$ in $\mathrm{CT}$ without contrast. The incidence of AKI in CT without contrast was similar to our study and higher than in CT with contrast. Hinson et al. [18], using the Acute Kidney Injury Network/Kidney Disease Improving Global Outcomes criteria, found that the probabilities of developing acute kidney injury were $6.8 \%, 8.9 \%$, and $8.1 \%$, in the contrast-enhanced CT, unenhanced CT, and non-CT groups, respectively. They measured serum creatinine $48-72 \mathrm{~h}$ after the procedure. In another study [19] in septic patients, the incidences of AKI were $7.2 \%, 9.4 \%$, and $9.7 \%$ in those who underwent CECT, unenhanced $\mathrm{CT}$, and no $\mathrm{CT}$, respectively. In both studies, the authors measured serum creatinine $48-72 \mathrm{~h}$ after the procedure. $\mathrm{CM}$ administration was not associated with an increased incidence of AKI. The authors concluded that their findings argued against withholding CM for fear of precipitating AKI in potentially septic patients. In a recent study, Gorelik et al. [20] reported that rate of AKI in patients undergoing CT with contrast with eGFR $<30 \mathrm{~mL} / \mathrm{min} / 1.73 \mathrm{~m}^{2}$ was $36 \%$, while in eGFR $>30 \mathrm{~mL} / \mathrm{min} / 1.73 \mathrm{~m}^{2}$ was $7.6 \%$, and in eGFR $30-44 \mathrm{~mL} / \mathrm{min} / 1.73 \mathrm{~m}^{2}$ was $19.8 \%$. The rate of AKI in CT without contrast in patients eGFR $<30 \mathrm{~mL} / \mathrm{min} / 1.73 \mathrm{~m}^{2}$ was $24.4 \%$. In their previous retrospective assessment of renal outcome in 12,580 hospitalized patients undergoing contrast-enhanced $\mathrm{CT}$, the rate of AKI was $8 \%$ [21]. In the prospective study of 1009 participants in the Swedish CArdioPulmonary bioImage Study (SCAPIS), PC-AKI was observed in only $1.2 \%$ according to the old ESUR criteria ( $>25 \%$ or $>44 \mu \mathrm{mol} / \mathrm{L}$ Scr increase) with creatinine measurement in 2-4 after the procedure [22]. Fukushima et al. [23] reported the incidence of CIN of $5.1 \%$ in 267 patients with eGFR below $60 \mathrm{~mL} / \mathrm{min} / 1.73 \mathrm{~m}^{2}$ within 3 days post-CT with contrast. Ellis et al. [24] reported that in patients with an eGFR less than $30 \mathrm{~mL} / \mathrm{min} / 1.73 \mathrm{~m}^{2}$, the proportion with post-CT AKI was $35 \%$ in contrast-enhanced CT and $14 \%$ unenhanced CT. However, in patients with an eGFR of $30-44 \mathrm{~mL} / \mathrm{min} / 1.73 \mathrm{~m}^{2}$, the proportion with post-CT AKI was $16 \%$ in the patients undergoing contrast-enhanced $\mathrm{CT}$ and $15 \%$ in the patients undergoing unenhanced CT. The higher rates of AKI than in our study ( $31 \%$ in the contrast vs. $34 \%$ in the non-contrast group) were reported recently in ICU patients by McDonald et al. [25]. Relevant studies are summarized in Table 7.

In addition, recently, there have been several studies in which the incidence of AKI was similar when compared with patients after contrast-enhanced computed tomography and non-enhanced computed tomography. As in our study, there was no evidence that the administration of an iodinated contrast media had an obvious effect on kidney function [26,27]. We look forward to the results of the INCARO study, the first randomized study on the effect of iodinated contrast agents in computed tomography on kidney function [28]. Due to the randomization and prospective design of the study, there is a chance that it will be the first referential assessment of the incidence of PC-AKI. However, until the end of the study (the recruitment of patients is estimated at 3 years), we must rely on observational and retrospective studies such as ours. 
At this point, we should consider the reason for the dramatic difference in the approach to post-contrast kidney injury. The first explanation may be the change in the osmolarity of the contrast agents. Initially, high-osmolar contrast media (HOCM) with proven nephrotoxic effects were predominantly used. The mechanism of PC-AKI is twofold: there is direct damage to the cell membrane of epithelial and endothelial cells and vasoconstriction through the release of cytokines and secondary hypoxia. Currently, iso-osmolar (IOCM) and low-osmolar contrast media (LOCM) are preferred, and thus such severe side effects are not observed $[5,9,27]$. Comparing the above-mentioned types of contrast agents, we found no significant differences in their influence on the development of PC-AKI. In addition, when analyzing the occurrence of PC-AKI, we should pay attention to two other risk factors connected to the procedure itself, i.e., the amount and method of administration of the contrast agent. The administration of contrast agents intravenously, as in computed tomography, is much safer than intra-arterial administration, which takes place during endovascular interventions. Interestingly, it seems that the amount of contrast media administered probably does not play a significant role in intravenous administration $[3,29]$.

Our goal is not to disregard the nephrotoxic effect of iodine contrast agents; rather, we would like to emphasize the need to change and standardize the current procedures, especially when performing computed tomography. At present, the ESUR Contrast Medium Safety Committee guidelines recommend the use of the eight-variable Mehran score to assess the safety of iodinated contrast media and prophylactic intravenous rehydration in people at risk of PC-AKI, such as renal failure (defined as eGFR $<60 \mathrm{~mL} / \mathrm{min} / 1.73 \mathrm{~m}^{2}$ ) [7]. Interestingly, although many studies have shown the nephroprotective effect of prophylactic hydration, the last large, randomized trial AMACING not only did not demonstrate the effectiveness of this procedure, but instead in some cases even proved its harmfulness [30].

\subsection{Study Limitations}

First, as serum creatinine was assessed in patients undergoing CT with or without intravenous contrast agent administration, we cannot extrapolate our results to coronary angiography or to percutaneous coronary interventions with intraarterial contrast administration. In addition, we studied changes in serum creatinine within 1-7 days, mainly 1 or 2 days, after $\mathrm{CT}$ to capture the early rise in serum creatinine as per definition. Many studies assess serum creatinine within several days. Second, our study was retrospective and single-center, but real-world data were gathered. In randomized controlled trials, patients represent selected populations with better compliance. In patients undergoing $\mathrm{CT}$, possible nephrotoxic drugs, i.e., (NSAIDs, diuretics, biguanidine derivatives in diabetic patients) were withdrawn, and RAAS blockers were either withdrawn (when blood pressure permitted) or halved $24 \mathrm{~h}$ before the procedure (in elective $\mathrm{CT}$ ), whereas aminoglycosides were administered extremely sparingly in our department. Among euvolemic and hypovolemic patients, whose clinical course permits it, we administer intravenous isotonic saline between 0.5 and $1 \mathrm{~L}$ before and after the procedure (time permitting), in total 1-2 L. We do not use acetylcysteine as a preventive measure. Hypervolemic patients and patients receiving dialysis in general are not given volume expansion (dialyzed patients were excluded from the analysis). The real-world data presented in our study could be either limitation or strength. Our findings may have important implications for the clinical management of patients undergoing CT. The "window of opportunity" is narrow in contrast nephropathy, and time is limited to introducing proper treatment after initiating insult as in a case of delayed graft function, particularly when patients are admitted for CT imaging and discharged within $24-48 \mathrm{~h}$ after the procedure. Third, we did not perform randomization, as actions for randomization for the type of $\mathrm{CT}$ with or without contrast were not feasible in this setting. Fourth, indication for CT (urgent vs. elective) reflects the clinical practice, and in some cases radiologists changed the mode taking into consideration the clinical scenario. In general, radiologists are relatively hesitant to perform $\mathrm{CT}$ with contrast in patients with impaired kidney function, and we do acknowledge that $\mathrm{CT}$ with contrast is performed on vital indication, as well as being fully aware of possible complications. However, we 
believe this is a strength of the study because it reflects daily clinical practice. Finally, the identification of periprocedural active infection, sepsis, or hemodynamic instability could not be retrieved directly from our database, and the precise volume and type of administered fluids could not be established. Furthermore, determination of eGFR on the basis of serum creatinine before and after imaging is limited in hospitalized patients with acute illnesses and with non-steady-state kidney function. Most importantly, there is likely a selection bias related to clinical judgment and decisions, for example, the avoidance of contrast-enhanced imaging in some patients with advanced renal functional impairment or performing contrast-enhanced imaging despite impaired renal function, considering the impact of enhanced imaging important enough to justify the administration of radiocontrast material, despite the risk of PC-AKI. In such patients, often with compound clinical conditions predisposing them to AKI, such as sepsis, hemodynamic instability, or exposure to other nephrotoxins, it may be impossible to differentiate the individual impact of a radiocontrast agent from the other clinical predisposing parameters, especially as PC-AKI is defined by the exclusion of other causes for deteriorating kidney function. The additional observation is that unwell patients with an urgent non contrast scan are at risk of AKI as a result of their clinical condition. The indications for $\mathrm{CT}$ are very different in the two groups, as are the baseline eGRF, and there were more urgent scans performed in the non-contrast group, with $43 \%$ having severe sepsis, which on its own may account for AKI. However, a prospective controlled study overcoming clinical judgment and decision-making on imaging strategies is likely not feasible; thus, our real-life data characterize clinical practice with a substantial component of uncertainties and possible confounders. Taking all these facts into consideration, we found that our real-world data provide an insight into the complicated problem of whether to perform CT with contrast or not, as well as trying to demystify the exaggerated threat of PC-AKI.

Moreover, due to the ambiguity of prophylaxis and current guidelines, in Poland, we cannot perform a contrast-enhanced computed tomography in patients with CKD on an outpatient basis. Unfortunately, therefore, patients may suffer from delayed diagnosis/treatment while waiting for hospitalization, and later to a hospital infection, often caused by multi-drug-resistant bacteria. In addition, we have repeatedly encountered a situation where non-enhanced CT was performed due to the fear of PC-AKI, but then contrast-enhanced CT was needed, exposing the patient to a higher radiation dose, because the previous examination was inconclusive. In general, patients with reduced glomerular filtration rate face the difficulties associated with performing CT with contrast. Internationally collected data points to the problem of not performing contrast-enhanced CT due to the fear of PC-AKI [13]. In the light of the new data, this fear seems to be ungrounded. The situation is similar in other risk groups in the field of oncology or transplantation, where caution needs to be exercised when administering iodinated contrast media, but it is not advisable to postpone the diagnosis because of fear of renal complications [31-33]. From our clinical perspective, if in CT with contrast will change the diagnosis, prognosis, and therefore outcome, it should be performed. Of course, and all necessary precautions should be taken.

Contrast-induced nephropathy (CIN) is an important drawback following the administration of intravascular iodinated contrast agents. Hospitalized patients do have a large number of comorbidities and are treated with a variety of nephrotoxic medications (antibiotics, analgesics, chemotherapeutics, and others). Therefore, their risk for CI-AKI is higher than ambulatory patients. CT scan with contrast should be performed if indicated as its denial or avoidance may delay diagnosis and proper treatment. Moreover, CT scan without contrast is often inconclusive and needs subsequent CT with contrast. Preventive measures should be introduced to prevent or minimize the risk of CI-AKI. In the worst-case scenario, renal replacement therapy is a viable option. 
Table 7. Relevant studies on the PC-AKI.

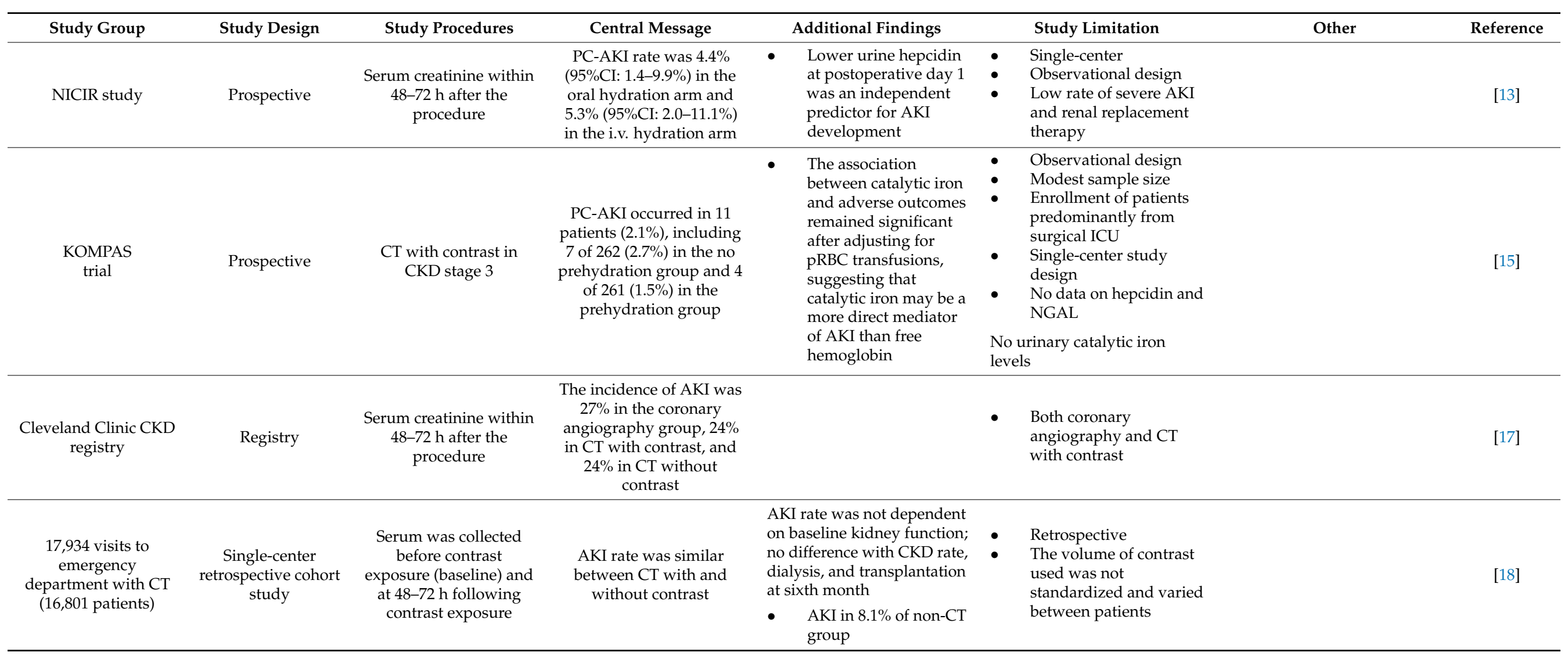


Table 7. Cont

\begin{tabular}{|c|c|c|c|c|c|c|c|}
\hline Study Group & Study Design & Study Procedures & Central Message & Additional Findings & Study Limitation & Other & Reference \\
\hline 11,516 patients & Meta-analysis & $\begin{array}{l}\text { Plasma samples were } \\
\text { obtained on days } 1 \text { and } \\
8 \text {, whereas hepcidin was } \\
\text { measured on day } 1 \text { only }\end{array}$ & $\begin{array}{l}\text { Higher plasma } \\
\text { concentrations of catalytic } \\
\text { iron and lower plasma } \\
\text { concentrations of } \\
\text { hepcidin were associated } \\
\text { with a significantly } \\
\text { greater risk of death }\end{array}$ & $\begin{array}{l}\text { Increased transferrin } \\
\text { saturation and higher } \\
\text { concentrations of } \\
\text { ferritin were also } \\
\text { associated with death, } \\
\text { but the magnitude of } \\
\text { association was } \\
\text { strongest for catalytic } \\
\text { iron and hepcidin } \\
\text { Lower transferrin was } \\
\text { associated with higher } \\
\text { catalytic iron } \\
\text { concentrations }\end{array}$ & $\begin{array}{ll}\text { - } & \text { Observational nature of } \\
\text { study } \\
\text { - } \quad \text { Lack of data on cause of } \\
\text { death } \\
\text { - } \quad \text { Unknown markers of } \\
\text { hemolysis } \\
\text { - } \quad \text { Lack of data on } \\
\text { intravenous iron } \\
\text { administration, } \\
\text { erythropoiesis- } \\
\text { stimulating agents, and } \\
\text { transfusion of packed } \\
\text { red blood cells }\end{array}$ & $\begin{array}{l}\text { - } \quad \text { Largest study to date } \\
\text { assessing dysregulated } \\
\text { iron homeostasis in the } \\
\text { context of human AKI } \\
\text { All patients enrolled in } \\
\text { the study had AKI } \\
\text { requiring RRT on } \\
\text { enrollment } \\
\text { - Assessment of multiple } \\
\text { iron parameters }\end{array}$ & [19] \\
\hline $\begin{array}{l}4171 \text { visits to ED, } 1640 \\
C T \text { with contrast, } 976 \\
\text { without contrast, and } \\
1731 \text { no } C T \text { at all }\end{array}$ & $\begin{array}{l}\text { Single-center, } \\
\text { propensity- } \\
\text { matched, } \\
\text { retrospective cohort } \\
\text { study }\end{array}$ & $\begin{array}{l}\text { Serum creatinine within } \\
48-72 \mathrm{~h} \text { after the } \\
\text { procedure }\end{array}$ & $\begin{array}{c}\text { The incidences of AKI } \\
\text { were } 7.2 \%, 9.4 \% \text {, and } 9.7 \% \\
\text { in those who underwent } \\
\text { CECT, unenhanced CT, } \\
\text { and no CT, respectively }\end{array}$ & $\begin{array}{l}\text { - Contrast } \\
\text { administration was } \\
\text { not associated with } \\
\text { the increased risk of } \\
\text { AKI }\end{array}$ & $\begin{array}{l}\text { - Only septic patients } \\
\text { Heterogeneous group }\end{array}$ & $\begin{array}{l}\text { - Sepsis as a medical } \\
\text { emergency was proven } \\
\text { to benefit from early } \\
\text { diagnosis and treatment } \\
\text { initiation, often aided by } \\
\text { CT with contrast }\end{array}$ & [19] \\
\hline $\begin{array}{c}\text { Enhanced MRI }=958, \\
\text { non-enhanced }=491, \\
\text { enhanced CT }=9576, \\
\text { non-enhanced } \\
\text { CT }=11,660\end{array}$ & $\begin{array}{l}\text { Propensity score } \\
\text { matching analysis }\end{array}$ & 22,321 imaging studies & $\begin{array}{l}\text { Patients with impaired } \\
\text { kidney function have a } \\
\text { greater risk of PC-AKI }\end{array}$ & $\begin{array}{l}\text { Anemia and diabetes are } \\
\text { risk factors for PC-AKI }\end{array}$ & $\begin{array}{ll}-\quad & \text { Selection bias } \\
\text { - } & \text { Retrospective data; } \\
\text { creatinine taken } 24-72 \mathrm{~h} \\
\text { after imaging }\end{array}$ & $\begin{array}{c}\text { Creatinine takes up to } 3 \text { days } \\
\text { before imaging }\end{array}$ & [21] \\
\hline $\begin{array}{l}1009 \text { patients form } \\
\text { SCAPIS study }\end{array}$ & Prospective & $\begin{array}{l}\text { Creatinine } \\
\text { measurement in 2-4 } \\
\text { after the angiography }\end{array}$ & $\begin{array}{l}\text { Iohexol is safe in patients } \\
\text { with eGFR }>50 \mathrm{~mL} / \mathrm{min}\end{array}$ & $\begin{array}{l}\text { PC-AKI rate very low } \\
\qquad(0.2 \%) ; \\
\text { no effect of diabetes and } \\
\text { NSAIDs use on AKI rate }\end{array}$ & $\begin{array}{ll}- & \text { Extension of blood } \\
\text { sampling to } 48-96 \mathrm{~h} \\
\text { while in ESUR criteria } \\
\text { within } 48-72 \mathrm{~h} \\
\text { Blood sampling before } \\
\text { angiography 0-91 days } \\
\text { (median 14 days) }\end{array}$ & $\begin{array}{c}\text { Very homogenous and } \\
\text { well-defined group aged } \\
50-65 \text { years }\end{array}$ & [22] \\
\hline
\end{tabular}


Table 7. Cont

\begin{tabular}{|c|c|c|c|c|c|c|c|}
\hline Study Group & Study Design & Study Procedures & Central Message & Additional Findings & Study Limitation & Other & Reference \\
\hline $\begin{array}{l}2583 \text { CT scans in } \\
2277 \text { patients }\end{array}$ & $\begin{array}{l}\text { Retrospective } \\
\text { cohort analysis }\end{array}$ & $\begin{array}{l}\text { The incidence of acute } \\
\text { kidney injury (Acute } \\
\text { Kidney Injury Network } \\
\text { stages) and dialysis } \\
\text { after acute kidney } \\
\text { injury were assessed in } \\
\text { the immediate period } \\
\text { (24-48 h) and in a } \\
\text { delayed period } \\
\text { (72-96 h) after the scan. }\end{array}$ & $\begin{array}{c}\text { AKI rate was not } \\
\text { dependent on CKD stage }\end{array}$ & $\begin{array}{c}\text { Dialysis after AKI was } \\
\text { similar across eGFR } \\
\text { subgroups. }\end{array}$ & $\begin{array}{l}\text { - } \quad \text { Only } 21 \text { patients with } \\
\text { CKD stage } 5 \text { and } 47 \text { with } \\
\text { CKD stage } 4 \\
\text { Restricted database; } \\
\text { some comorbidities may } \\
\text { be missing, as well as } \\
\text { nephrotoxic drugs, } \\
\text { contrast agent volume, } \\
\text { and prophylaxis } \\
\text { regimen }\end{array}$ & & [34] \\
\hline $\begin{array}{l}2008 \text { on adult patients } \\
\text { who underwent a } \\
\text { contrast-enhanced } \\
\text { computed } \\
\text { tomography for } \\
\text { urgent diagnostic } \\
\text { purposes. }\end{array}$ & $\begin{array}{l}\text { Single-center } \\
\text { retrospective } \\
\text { analysis }\end{array}$ & $\begin{array}{l}\text { Creatinine assessment } \\
\text { within } 48 \mathrm{~h}\end{array}$ & $\begin{array}{l}\text { PC-AKI was a frequent } \\
\text { complication } \\
(16.8 \%)\end{array}$ & $\begin{array}{c}\text { Sepsis, nephrotoxic drugs, } \\
\text { and hemodynamic } \\
\text { failure-risk factors for AKI } \\
\text { PC-AKI associated with ICU } \\
\text { mortality; } \\
\text { need for renal replacement } \\
\text { therapy in } 29.2 \% \text { of PC-AKI }\end{array}$ & $\begin{array}{ll}- & \text { Retrospective } \\
\text { - } & \text { No data on contrast } \\
& \text { volume, no data on } \\
& \text { prophylaxis, } \\
\text { - } & \text { Mixed medical-surgical } \\
& \text { ICU population } \\
\text { - } & \text { Urgent procedure } \\
\text { - } & \text { Repeated } \\
\text { administrations of } \\
\text { contrast were not } \\
\text { assessed } \\
\text { Fluid balance and } \\
\text { hemodilution were not } \\
\text { assessed }\end{array}$ & & [35] \\
\hline $\begin{array}{c}8 \text { articles out of } \\
2500 \text { screened were } \\
\text { analyzed }\end{array}$ & $\begin{array}{l}\text { Systemic review } \\
\text { (meta-analysis of } \\
\text { observational } \\
\text { studies) }\end{array}$ & $\begin{array}{c}\text { Incidence of } \\
\text { post-contrast acute } \\
\text { kidney injury (AKI) } \\
\text { following intravenous } \\
\text { contrast agent } \\
\text { administration }\end{array}$ & $\begin{array}{c}\text { CT with contrast was not } \\
\text { significantly associated } \\
\text { with AKI. }\end{array}$ & $\begin{array}{l}\text { Risk of contrast induced } \\
\text { nephropathy (CIN) was } \\
\text { negligible in patients with } \\
\text { normal renal function, but } \\
\text { the incidence appeared to } \\
\text { rise to as high as } 25 \% \text { in } \\
\text { patients with pre-existing } \\
\text { renal impairment or in the } \\
\text { presence of risk factors such } \\
\text { as diabetes, advanced age, } \\
\text { vascular disease, and use of } \\
\text { certain concurrent } \\
\text { medications }\end{array}$ & $\begin{array}{l}\text { Systematic review addressed } \\
\text { both CIN and PC-AKI because } \\
\text { in literature the two terms } \\
\text { CIN from PC-AKI were } \\
\text { difficult to separate, even if } \\
\text { these terms were not } \\
\text { interchangeable }\end{array}$ & $\begin{array}{l}\text { The incidence reported of AKI } \\
\text { in patients undergoing cCT } \\
\text { with contrast was not as high } \\
\text { as thought before }\end{array}$ & [36] \\
\hline
\end{tabular}


Table 7. Cont.

\section{Study Group}

Study Design

\section{Study Procedures}

Central Message Additional Findings

The high incidence of CI-AKI in the elderly was consistent across differen administration route 67,831 patients older than 65 years of age (out of 186, Meta-analysis (22 studies)

Incidence of AKI in elderly (over 65 years)

Incidence of CI-AKI was subgroups (intracoronary contrast medium group, $15.5 \%$; intravenous contrast medium group, $12.4 \%$ ) $13.6 \%$ in the elderly

\section{Study Limitation}

Incomplete data on risk

factors for AKI

- Definitions of elderly and CI-AKI varied among the included studies, which brought heterogeneity

- $\quad$ No age-stratified

subgroup analysis

AKI as vast majority of

AKI as vast majority of

used the definition

based on serum

creatinine alone and

without grading

Retrospective

- $\quad$ Exclusion of $37 \%$ of

eligible subjects

eligible subjects
$(1298 / 3538)$ because

(1298/3538) because
creatinine levels

immediately after CT

were unavailable

eGFR, diabetes mellitus,

and serum albumin level

Diagnosis or

Development of the prediction measurement within were risk factor for AKI$$
\text { elderly are available }
$$

No data regarding the impact of CI-AKI on a patient's clinical course and prognosis, and no conclusive Reference

prescription codes were

used, but their accuracy

in representing clinical

information was not

well validated 


\subsection{Key Findings and Future Directions}

AKI was more common in the non-enhanced CT population.

It appears that PC-AKI is not a great risk for patients, even those with chronic kidney disease.

The fear of using contrast agents seems to be exaggerated.

Prospective studies on large population with various stages of CKD are needed to prove or disprove the detrimental effects of contrast agents on kidney function.

\section{Materials and Methods}

In our study, we analyzed all computed tomography performed in our department in 2019. Patients were qualified for the study according to indication, taking into account clinical benefits, and not with regard to renal function. In each case, we recorded basic information characterizing the $\mathrm{CT}$ and the patient, referring to known potential factors increasing the risk of post-contrast acute kidney injury. We noted the type (with or without contrast), the scope of examination, and the mode in which the examination was performed (emergency or routine). As for patient-dependent factors, age, sex, and comorbidities were recorded, including the determination of kidney function by measurement of serum creatinine concentration and eGFR (calculated using CKD-EPI formula). Then, in each case, it was observed whether the parameters of renal function were checked after CT in three time periods: $1-7,14-28$, and over 28 days. It was not possible to trace previous parameters of kidney function in most cases as it was the first hospitalization or there was no adequate medical documentation. Cases where no follow-up examinations were recorded in any of the above-mentioned time periods were excluded from further analysis. Moreover, patients with end-stage renal disease treated with dialysis were excluded.

The remaining cases were divided into two groups-patients undergoing contrastenhanced CT and non-enhanced CT. In order to make the analysis more reliable, we reduced the larger group of patients so that the number of patients in each group was similar, and both groups had to represent similar criteria, such as age, sex, and comorbidities. After obtaining two clinically comparable groups, we recorded the number of cases with AKI in each instance. For this purpose, the KDIGO criteria were used (increase in serum creatinine concentration $\geq 0.3 \mathrm{mg} / \mathrm{dL}$ or $\geq 1.5-1.9$ times the baseline value), in accordance with the applicable guidelines. Cases in which AKI developed later after CT than assumed in the definition of PC-AKI were also considered. The situations in which AKI developed later after CT than assumed in the definition of PC-AKI were also considered. This solution was chosen due to fact that in many cases did not undergo a follow-up examination $48-72 \mathrm{~h}$ after CT-our study is retrospective, and in Poland, parameters of renal function are not routinely monitored after $\mathrm{CT}$, especially non-enhanced cases. It should also be taken into account that the increase in renal parameters occurs 48-72 after the administration of an iodinated contrast media; however, the duration of AKI is variable and may even cause permanent renal failure. Additionally, we concluded that if the contrast caused AKI significantly more often in our patients, we would notice it regardless of the assumed time frame.

In each identified case of AKI after $\mathrm{CT}$, a possible cause was searched for on the basis of the available medical documentation. As a result, more accurate information on the development of contrast-induced acute kidney injury in the study group was obtained.

Author Contributions: Conceptualization: I.C. and J.M.; methodology: J.M.; investigation: I.C., M.K., and A.L.; formal analysis: I.C., M.K., and A.L.; writing-original draft preparation: I.C.; writing-review and editing: J.M. All authors have read and agreed to the published version of the manuscript.

Funding: This research received no external funding.

Institutional Review Board Statement: Not applicable.

Informed Consent Statement: Not applicable. 
Data Availability Statement: The data presented in this study are available on request from the corresponding author.

Conflicts of Interest: The authors declare no conflict of interest.

\section{References}

1. Zamora, C.A.; Castillo, M. Historical Perspective of Imaging Contrast Agents. Magn. Reason. Imaging Clin. N. Am. 2017, 25, 685-696. [CrossRef] [PubMed]

2. Bartels, E.D.; Brun, G.C.; Gammeltoft, A.; Gjorup, P.A. Acute anuria following intravenous pyelography in a patient with myelomatosis. Acta Med. Scand. 1954, 150, 297-302. [CrossRef]

3. van der Molen, A.J.; Reimer, P.; Dekkers, I.A.; Bongartz, G.; Bellin, M.F.; Bertolotto, M.; Clement, O.; Heinz-Peer, G.; Stacul, F.; Webb, J.A.W.; et al. Post-contrast acute kidney injury-Part 1: Definition, clinical features, incidence, role of contrast medium and risk factors: Recommendations for updated ESUR Contrast Medium Safety Committee guidelines. Eur. Radiol. 2018, 28, 2845-2855. [CrossRef] [PubMed]

4. $\quad$ Davenport, M.S.; Perazella, M.A.; Yee, J.; Dillman, J.R.; Fine, D.; McDonald, R.J.; Rodby, R.A.; Wang, C.L.; Weinreb, J.C. Use of Intravenous Iodinated Contrast Media in Patients with Kidney Disease: Consensus Statements from the American College of Radiology and the National Kidney Foundation. Radiology 2020, 294, 660-668. [CrossRef] [PubMed]

5. Luk, L.; Steinman, J.; Newhouse, J.H. Intravenous Contrast-Induced Nephropathy-The Rise and Fall of a Threatening Idea. Adv. Chronic Kidney Dis. 2017, 24, 169-175. [CrossRef] [PubMed]

6. Thomsen, H.S.; Morcos, S.K. Contrast media and metformin: Guidelines to diminish the risk of lactic acidosis in non-insulindependent diabetics after administration of contrast media. ESUR Contrast Media Safety Committee. Eur. Radiol. 1999, 9, 738-740. [CrossRef] [PubMed]

7. van der Molen, A.J.; Reimer, P.; Dekkers, I.A.; Bongartz, G.; Bellin, M.F.; Bertolotto, M.; Clement, O.; Heinz-Peer, G.; Stacul, F.; Webb, J.A.W.; et al. Post-contrast acute kidney injury. Part 2: Risk stratification, role of hydration and other prophylactic measures, patients taking metformin and chronic dialysis patients: Recommendations for updated ESUR Contrast Medium Safety Committee guidelines. Eur. Radiol. 2018, 28, 2856-2869. [CrossRef]

8. Elicker, B.M.; Cypel, Y.S.; Weinreb, J.C. IV contrast administration for CT: A survey of practices for the screening and prevention of contrast nephropathy. Am. J. Roentgenol. 2006, 186, 1651-1658. [CrossRef]

9. Do, C. Intravenous Contrast: Friend or Foe? A Review on Contrast-Induced Nephropathy. Adv. Chronic Kidney Dis. 2017, 24, 147-149. [CrossRef]

10. Chomicka, I.; Kwiatkowska, M.; Małyszko, J. Post-contrast acute kidney injury following computed tomography: A real or overestimated threat? Pol. Arch. Intern. Med. 2020, 130, 704-707.

11. Stevens, P.E.; Levin, A. Kidney Disease: Improving Global Outcomes Chronic Kidney Disease Guideline Development Work Group Members. Evaluation and management of chronic kidney disease: Synopsis of the kidney disease: Improving global outcomes 2012 clinical practice guideline. Ann Intern Med. 2013, 4, 825-830. [CrossRef] [PubMed]

12. Kooiman, J.; Pasha, S.M.; Zondag, W.; Sijpkens, Y.W.; van der Molen, A.J.; Huisman, M.V.; Dekkers, O.M. Meta-analysis: Serum creatinine changes following contrast enhanced CT imaging. Eur. J. Radiol. 2012, 81, 2554-2561. [CrossRef]

13. Moos, S.I.; van Vemde, D.N.; Stoker, J.; Bipat, S. Contrast induced nephropathy in patients undergoing intravenous (IV) contrast enhanced computed tomography (CECT) and the relationship with risk factors: A meta-analysis. Eur. J. Radiol. 2013, 82, e387-e399. [CrossRef] [PubMed]

14. From, A.M.; Bartholmai, B.J.; Williams, A.W.; Cha, S.S.; Pflueger, A.; McDonald, F.S. Sodium bicarbonate is associated with an increased incidence of contrast nephropathy: A retrospective cohort study of 7977 patients at mayo clinic. Clin. J. Am. Soc. Nephrol. 2008, 3, 10-18. [CrossRef]

15. Timal, R.J.; Kooiman, J.; Sijpkens, Y.W.J.; de Vries, J.P.P.M.; Verberk-Jonkers, I.J.A.M.; Brulez, H.F.H.; van Buren, M.; van Der Molen, A.J.; Cannegieter, S.C.; Putter, H.; et al. Effect of No Prehydration vs. Sodium Bicarbonate Prehydration Prior to ContrastEnhanced Computed Tomography in the Prevention of Postcontrast Acute Kidney Injury in Adults With Chronic Kidney Disease: The Kompas Randomized Clinical Trial. JAMA Intern. Med. 2020, 180, 533-541. [CrossRef] [PubMed]

16. Sebastià, C.; Páez-Carpio, A.; Guillen, E.; Paño, B.; Garcia-Cinca, D.; Poch, E.; Oleaga, L.; Nicolau, C. Oral hydration compared to intravenous hydration in the prevention of post-contrast acute kidney injury in patients with chronic kidney disease stage IIIb: A phase III non-inferiority study (NICIR study). Eur. J. Radiol. 2021, 136, 109509. [CrossRef]

17. Chaudhury, P.; Armanyous, S.; Harb, S.C.; Provenzano, L.F.; Ashour, T.; Jolly, S.E.; Arrigain, S.; Konig, V.; Schold, J.D.; Navaneethan, S.D.; et al. Intra-Arterial versus Intravenous Contrast and Renal Injury in Chronic Kidney Disease: A PropensityMatched Analysis. Nephron 2019, 141, 31-40. [CrossRef]

18. Hinson, J.S.; Ehmann, M.R.; Fine, D.M.; Fishman, E.K.; Toerper, M.F.; Rothman, R.E.; Klein, E.Y. Risk of Acute Kidney Injury After Intravenous Contrast Media Administration. Ann. Emerg. Med. 2017, 69, 577-586. [CrossRef] [PubMed]

19. Hinson, J.S.; Al Jalbout, N.; Ehmann, M.R.; Klein, E.Y. Acute kidney injury following contrast media administration in the septic patient: A retrospective propensity-matched analysis. J. Crit. Care 2019, 51, 111-116. [CrossRef]

20. Gorelik, Y.; Yaseen, H.; Heyman, S.N.; Khamaisi, M. Negligible Risk of Acute Renal Failure among Hospitalized Patients After Contrast-Enhanced Imaging With Iodinated Versus Gadolinium-Based Agents. Investig. Radiol. 2019, 54, 312-318. [CrossRef] 
21. Gorelik, Y.; Bloch-Isenberg, N.; Yaseen, H.; Heyman, S.N.; Khamaisi, M. Acute Kidney Injury after Radiocontrast-Enhanced Computerized Tomography in Hospitalized Patients with Advanced Renal Failure: A Propensity-Score-Matching Analysis. Investig. Radiol. 2020, 55, 677-687. [CrossRef]

22. Carlqvist, J.; Nyman, U.; Sterner, G.; Brandberg, J.; Fagman, E.; Hellström, M. Minimal risk of contrast-induced kidney injury in a randomly selected cohort with mildly reduced GFR. Eur. Radiol. 2020, 31, 3248-3257. [CrossRef] [PubMed]

23. Fukushima, Y.; Miyazawa, H.; Nakamura, J.; Taketomi-Takahashi, A.; Suto, T.; Tsushima, Y. Contrast-induced nephropathy (CIN) of patients with renal dysfunction in CT examination. Jpn. J. Radiol. 2017, 35, 427-431. [CrossRef] [PubMed]

24. Ellis, J.H.; Khalatbari, S.; Yosef, M.; Cohan, R.H.; Davenport, M.S. Influence of Clinical Factors on Risk of Contrast-Induced Nephrotoxicity From IV Iodinated Low-Osmolality Contrast Material in Patients With a Low Estimated Glomerular Filtration Rate. AJR Am. J. Roentgenol. 2019, 213, W188-W193. [CrossRef]

25. McDonald, J.S.; McDonald, R.J.; Williamson, E.E.; Kallmes, D.F. Is Intravenous Administration of Iodixanol Associated with Increased Risk of Acute Kidney Injury, Dialysis, or Mortality? A Propensity Score-adjusted Study. Radiology 2017, 285, 414-424. [CrossRef]

26. Tao, S.M.; Wichmann, J.L.; Schoepf, U.J.; Fuller, S.R.; Lu, G.M.; Zhang, L.J. Contrast-induced nephropathy in CT: Incidence, risk factors and strategies for prevention. Eur. Radiol. 2016, 26, 3310-3318. [CrossRef] [PubMed]

27. Aycock, R.D.; Westafer, L.M.; Boxen, J.L.; Majlesi, N.; Schoenfeld, E.; Bannuru, R.R. Acute Kidney Injury After Computed Tomography: A Meta-analysis. Ann. Emerg. Med. 2018, 71, 44-53.e4. [CrossRef]

28. Räty, P.; Mentula, P.; Lampela, H.; Nykänen, T.; Helanterä, I.; Haapio, M.; Lehtimäki, T.; Skrifvars, M.B.; Vaara, S.T.; Leppäniemi, A.; et al. INtravenous Contrast computed tomography versus native computed tomography in patients with acute Abdomen and impaired Renal functiOn (INCARO): A multicentre, open-label, randomised controlled trial-study protocol. BMJ Open 2020, 10, e037928. [CrossRef]

29. Hiremath, S.; Kong, J.; Clark, E.G. Contrast and acute kidney injury: What is left to enhance? Nephrol. Dial. Transplant. 2020, 10, gfaa183. [CrossRef]

30. Nijssen, E.C.; Rennenberg, R.J.; Nelemans, P.J.; Essers, B.A.; Janssen, M.M.; Vermeeren, M.A.; Ommen, V.V.; Wildberger, J.E. Prophylactic hydration to protect renal function from intravascular iodinated contrast material in patients at high risk of contrastinduced nephropathy (AMACING): A prospective, randomised, phase 3, controlled, open-label, non-inferiority trial. Lancet 2017, 389, 1312-1322. [CrossRef]

31. Cosmai, L.; Porta, C.; Privitera, C.; Gesualdo, L.; Procopio, G.; Gori, S.; Laghi, A. Acute kidney injury from contrast-enhanced CT procedures in patients with cancer: White paper to highlight its clinical relevance and discuss applicable preventive strategies. ESMO Open 2020, 5, e000618. [CrossRef]

32. Mangus, R.S.; Bajpai, S.; Lutz, A.J.; Powelson, J.A.; Goggins, W.C. Contrast Administration to the Deceased Kidney Donor Has No Impact on Post-Transplant Outcomes. J. Surg. Res. 2020, 254, 261-267. [CrossRef] [PubMed]

33. Benjamens, S.; Yakar, D.; Slart, R.H.J.A.; Sanders, J.S.F.; Pol, R.A. The fear for contrast-induced nephropathy in kidney transplant recipients: Time for a paradigm shift? Transpl. Int. 2018, 31, 1050-1051. [CrossRef]

34. Garfinkle, M.A.; Stewart, S.; Basi, R. Incidence of CT Contrast Agent-Induced Nephropathy: Toward a More Accurate Estimation. AJR Am. J. Roentgenol. 2015, 204, 1146-1151. [CrossRef] [PubMed]

35. Clec'H, C.; Razafimandimby, D.; Laouisset, M.; Chemouni, F.; Cohen, Y. Incidence and outcome of contrast-associated acute kidney injury in a mixed medical-surgical ICU population: A retrospective study. BMC Nephrol. 2013, 14, 31. [CrossRef]

36. De Simone, B.; Ansaloni, L.; Sartelli, M.; Gaiani, F.; Leandro, G.; Luigi de' Angelis, G.; Di Mario, F.; Coccolini, F.; Catena, F. Is the risk of contrast-induced nephropathy a real contraindication to perform intravenous contrast enhanced Computed Tomography for non-traumatic acute abdomen in Emergency Surgery Department? Acta Biomed. 2018, 89, 158-172. [PubMed]

37. Song, W.; Zhang, T.; Pu, J.; Shen, L.; He, B. Incidence and risk of developing contrast-induced acute kidney injury following intravascular contrast administration in elderly patients. Clin. Interv. Aging 2014, 9, 85-93.

38. Jeon, J.; Kim, S.; Yoo, H.; Kim, K.; Kim, Y.; Park, S.; Jang, H.R.; Kim, D.K.; Huh, W.; Kim, Y.G.; et al. Risk Prediction for Contrast-Induced Nephropathy in Cancer Patients Undergoing Computed Tomography under Preventive Measures. J. Oncol. 2019, 2019, 8736163. [CrossRef] 